\title{
A Systematic Review of Celebrity Effect and Its Impact On the Consumer Economy
}

\author{
Yumin $\operatorname{Sun}^{1, *}$ \\ ${ }^{1}$ Wycombe Abbey School Changzhou, Jiangsu, China \\ *Corresponding author. Email: 13.jessie.sun@waiscz.com
}

\begin{abstract}
Throughout the celebrity endorsement world, including the general audience and the media, use their attention to form the values and achievements of all celebrities and to focus on celebrity-approved products, a shift in their vision from one commodity to another. Attracting the masses and fans will support consumption and promote economic development. However, rational audiences, after meeting their visual needs and considering maximizing their benefits, are likely not to contribute to the money spent by celebrities. After ensuring that celebrity advertising attracts a lot of public attention, companies also need to invest more to introduce high-demand, high-quality, purposeful and creative products to make eye-catching celebrity posters fully realize their value. Similarly, the influence of the domestic media in all its forms is enormous, and young people can easily be blindly swallowed up by the strong publicity and trust of their favorite celebrities before forming a mature view. Therefore, young people should establish a correct concept of consumption, rational treatment of celebrity endorsement, according to their own needs to choose to buy products.
\end{abstract}

Keywords: Celebrity endorsement, Economy, Influence, Media, Advertisement.

\section{INTRODUCTION}

Celebrity is considered as a kind of social relation and visual demand that gathers public's attention and turns it into value [1]. They become precious and celebrated because of the attention attracted from ordinary people and the media. Celebrity endorsement is actually a special example of a more general meaning transfer process; it refers to individual owning public recognition and represent consumer goods in advertisements using this recognition [2]. In advertising marketing, from being recognized, trusted, purchased to gaining reputation, popularity and credibility are the essences of publicizing products. Popularity is related to attention; trustworthiness depends on advertising campaign, which is a series of similar advertisements, and each one has a different theme, issued by a company or enterprise with the same core information, but also persuade consumers to buy their products, and match-up hypothesis [3].

The research combines visual with commercial, connects celebrity endorsements and promotional posters. For example,Li Jiaqi, he is a "lipstick brother" and a "devil boy". He is the e-commerce live industry's undisputed leader, the real "national goods king." The e- commerce anchor represented by him, so that the traditional e-commerce is once again empowered and lit up, become the post-epidemic era of the new economy the most dazzling bright color. Pindo, founded in September 2015, users through the launch and friends, family, neighbors, etc., can be lower prices, group to buy high-quality goods. Designed to rally more people, with lower prices to buy better things, experience more benefits and fun. Through communication and sharing formed the social concept, formed a multi-unique new social e-commerce thinking.

It mainly focuses on how celebrities reflect and achieve the two essences of advertising, as well as the cultural and economic connection existing between the image or personality of celebrities, the roles they play and the products they build with their own names and reputation from three main angles of view of the matching degree of stars and advertisements, the display of glamour and gender values. This is a necessary exploration of the relationship between the celebrity and advertisement from multiple perspectives. The existing researches mainly focused on the product placement in movies itself, and most of them were quantitative researches, which provided a broad academic background for our research. Nevertheless, the existing 
researches were limited in the some specific examples. Most of the research is now in case study, and our point of view is to compare, in-depth cases. Celebrities are closely related to the general public, who not only set an example, but also to some extent promoted the economy of cities and even countries. Celebrities are closely related to the general public, who not only set an example, but also to some extent promoted the economy of cities and even countries. Our article does a systematic review to analyze the current state of celebrity influence, including how to spend rationally. Furthermore, by analyzing and connecting consumers, business people, celebrities themselves and the changes in the Netflix economy and national economic policy.

\section{METHOD}

In this review article, the GMF surveys and data analysis were referenced in related research articles, journals, academic websites, and government websites. From those resources, the new discoveries and further researches will be illustrated in this review article.

\section{THE INFLUENCE OF CELEBRITIES IN MEDIA AND ECONOMIC}

\subsection{Reason that celebrities can become celebrities compared with average people - Media / ordinary people}

Going back to the concept of celebrity, celebrity is a social relation that converts attention into value because of its role in the public and its connection to business [1]. Celebrities put more emphasis on the "mass" concept; with celebrities themselves as the center and fans spreading more influence as a radius, originally scattered and independent masses form a inflential circle representing the mass group. Public's gazes bring up celebrities, therefore some ordinary people try to obtain eyeballs by extreme ways such as hype, pretending to be ill and making up fake news. As a traditional celebrity, the public always matches them with their positions, talents and status and focuses on them. However, in the process of celebrities becoming famous, more and more news related to them and even their private lives unrelated to their careers are constantly revealed. Therefore, while being reported, celebrities are composed of attention and become commodities. Inspired by Jonathan Beller's point of view, under the commodity of celebrity, audience becomes numb, mechanized and thoughtless, paying out labor without remuneration. The difference between celebrities and ordinary people is in need of media attention which becomes the primary condition for ordinary people to cross the huge gap to be celebrities. Without the media, stars cannot get more exposure, subsequently become part of the masses without characteristics and attention.
The commodity of celebrity needs the support of media coverage.

Didi Huberman mainly expounds that stars are defined, recognized and identified in screens of television and film, while their appearance in any specific scene promotes the development of media [4]. The media is determined to show the valuable theme or story of the star. Popular culture sociologist Laura greenstaff believes that "ordinary" does not mean that the content is "ordinary", "typical" or "representative of the general population", but just conveys that they are not experts or celebrities, who are famous for various reasons, such as experiencing major events and willing to share them with the public. Ordinary people, that is, extras, do not constitute any performance power or narrative value for the media. In this social stratification, they are constructed as the background environment to decorate the image of the leading role. There is a film without actors which is dedicated to its extra and about people willing to work in cinema tells the desire for cinema. Similarly, a documentary about the workers behind the manufacturing of goods brought the hidden lives of ordinary people to the screen, demonstrating a backlash against the media's choice of celebrities as mainstream. Compared with celebrities who are bound by their eyes, limited in behavior and strict in hierarchy, ordinary people are considered to be a group of people with more real and strong emotions, while the daily life or real performance constructed under the traditional media industry is just a planned and packaged entertainment product in the eyes of the public. These days, numerous advertisements use celebrity actors to play the roles of ordinary people, trying to let ordinary people resonate with the products and have a daily, real feeling.

Celebrities are diverse, rich in forms, valuable for appreciation or attraction. Reality TV celebrity, DIY celebrity, microcelebrity and Internet celebrity as branches of celebrities, all play a role of generating value in different kinds of fields [5]. In the 2010s, mainstream media coverage and discussion of influencers focused on a particular type of celebritythe influencer, which are the epitome of Internet celebrities because they make a living from them. Internet celebrities (also known as social media influencers ) refer to celebrities who obtain or develop their reputation and popularity through the Internet [6]. In the past decade or so, this group has developed into a variety of forms, developing in an all-round way in various fields such as food, sports, beauty, life, games, film and television, and using various platforms such as youtube, twitter, BiliBili, instagram and Facebook to realize viral communication through video or pictures. The Chinese call internet celebrities "wanghong" which has a translation of "red in the internet": the color red means a large number of views and active user groups, representing the high popularity and wide attention of 
such groups compared with ordinary people. The popularity of online celebrities is closely related to their cultural concept, target audience and recognition; When the content cannot be viewed, disseminated and recognized, no matter how much it costs or how high the quality of the content is, the publisher cannot become a successful internet celebrity. Internet celebrity reaps advertisements, endorsements or more commercial activities to turn the original visual user traffic into money. Traditional celebrities are increasingly moving their content from traditional media to social media to appeal to a wider audience.

\subsection{The essences of propaganda in advertising marketing - popularity and credibility}

The celebrity economy is a sort of attention economy. Temporary attention will be caused by these stars, so how can non fans focus on the content of products in posters rather than mechanized faces in the long run? Li Jiaqi, who recently burst into flames, is a good example. When it comes to Li Jiaqi, most people's impression stays at: flamboyant, hyped, "OMG buys it". But the truth is even more striking is that he has raised $\$ 14$ million in two months with a short video, and a quivering ad has cost $\$ 950,000$; from a monthly salary of just $4 \mathrm{k}$ to a top-of-the-line bonus of tens of millions a year, it took only three years; and a live stream of $250 \mathrm{w}$ Five minutes to sell 15,000 lipsticks, five hours to win 3.53 million marketing, seconds to kill Jack Ma [7].... Many people blame Li Jiaqi's success on luck, value, and it is an important factor in Li Jiaqi's success is: he saw the huge wind of live video, choose the right direction and keep working hard. Although the ecommerce model has changed the traditional offline shopping mode, making shopping more convenient and the price more transparent, but the graphic-based presentation is too abstract, consumers can not carry out physical, detailed understanding of commodity information. In terms of presentation, it's video better than pictures than text. And the new consumption scene of live shipping perfectly makes up for the defects of graphics, the information dimension of live broadcast is richer, so that consumers as immersive, more intuitive understanding of product information. The biggest advantage of live streaming is that it integrates consumers into the shopping scene.

Pindo is also the latest rise of the app, compared to the more popular Taobao and JD.com, Alibaba and Pindo released the same day the first quarter report, although the first quarter of the two companies' revenue performance exceeded expectations, but reflected in the stock market is very different, Alibaba closed the day down 5.87 percent, the market value evaporated $\$ 33.5$ billion, while the market value increased by 14.5 percent [8]. Money is the smartest, and the stock price performance of both shows how much the market is bullish about the world, which is known for its cheapness.

Combined with the situation of Li Jiaqi and Pindo, we look to see that the recent fire of things have a characteristic: cheap. It is common that people does not how much to sell the quality of the product, but the price is absolutely cheap, Via, Li Jiaqi live sales of products are also low-cost goods. What does that mean? Cheap things can be recognized in the market, people can no longer pursue the so-called high quality. To be more blunt: the people have no money! It is difficult to know whether we have heard of the "lipstick economy", is Li Jiaqi with the most of that lipstick, once the sales of lipstick skyrocketed, meaning that the recession is coming, of course, we say that Li Jiaqi dragged down the economy is not accurate, but Li Jiaqi's enthusiasm foreshadowed the beginning of the economic downturn. It is precisely because celebrities themselves have the characteristics of mixed reviews and high profile that product companies have focused on celebrity endorsement. They seem to be a major way for the public to understand products. Celebrity endorsement is actually a special example of a more general meaning transfer process; It refers to individual owning public recognition and represent consumer goods in advertisements using this recognition [9]. An individual who is well known by masses in any field other than marketing of the product is called a celebrity endorser. During the process a greater audiences especially fan group are drawn. A simple example is listed here: on the social platform Weibo, the likes of a bedding brand on Weibo are usually in the hundreds, and the forwarding amount is just double digit. When a famous Chinese actor became the endorser, the official Weibo account received millions of likes and retweets, while the celebrity's weibo account received more than six million likes with millions of comments and retweets. It doesn't even take 24 hours for the brand to go from being unknown to being involved with an entire fan base, and sales have grown dramatically along with popularity. In advertising marketing, from being recognized, trusted, purchased to gaining reputation, popularity and credibility are the essences of publicizing products.

The so-called lipstick economy, that is, women as the main consumer, give up the purchase of houses, purses, coats and other luxury high-priced goods, into the purchase of cheap but still can maintain their own beautiful temperament of goods, of which lipstick is the best choice. A lipstick dozens of pieces, up to a few hundred dollars, there are a variety of colors to choose from, so that they still shine. Lipstick is the most costeffective compared to bags and expensive clothes. Perhaps many people do not like Li Jiaqi, Via, more than, but they sell goods are accurate and cheap, so under the guidance of the wallet, he (it) into the eyes of people, you just passively choose him (it), who do not 
want high-quality goods? Li Jiaqi's success is a necessity in the economic situation, even without $\mathrm{Li}$ Jiaqi, there will be Wang Jiaqi, his fiery, just hints at the economic downturn and recession. If we want to change that, we must not limit oursself to the role of one person or one star, whose back is the entire country's economic system.

\subsection{The communication and interaction between celebrity endorsement and consumers}

Successful advertising often has profound cultural connotation and value, which promotes the progress of the times. In China, many opinion advertisements and public service advertisements have been produced to advocate ideas from a social perspective, carry forward China's traditional culture and publicize the national image. Invite celebrities with positive energy to participate in advertising, enhance popularity and realize the cultural value of advertising.

In advertising marketing, consumers and celebrity endorsers establish contact and communication through products. In front of consumers, all the business has to do is make them believe in the product. To be exact, celebrities use the characteristics of a commodity to share their attention with another commodity. Actually, the matching between celebrity and product is the key factor to test the effectiveness of celebrity endorsement: the study found that celebrity product pairing had a positive impact on various celebrity, advertising and brand-related ratings. The Match-up is also regarded as congruency, similarity and relevance, refering to the similarity or consistency between celebrity and product category, which is the primary condition for the success of marketing communication [10]. This match-up hypothesis states that there should be a strong match between the celebrity image and the product image, as their compatibility affects the persuasiveness of advertisements [11]. When celebrities endorse a product, consumers will think about the matching and relationship between celebrities and products. If celebrities are not associated with the product, for example, a male traffic star endorses female product, the credibility of the product is difficult to improve. To avoid trouble, expertise choose suitable celebrities to endorse products that match their status or image. Michael Jordan and Tiger Woods endorse the sports brand Nike, young actress Yang Mi endorse Estee Lauder. The matching of product and spokesperson is more likely to persuade consumers to buy the recognized brand by transferring the cultural meaning of its brand image to the product. Connections are forged by the capacity, habits of celebrities and the actual use of the product by them. The closer the connection or the better the degree of match, the higher people's trust in advertising.
The film "the Way of Seeing" explains The reflection of capitalism and reality hidden behind advertisements and facial surfaces. Attractiveness, jealousy and reflected desire were mentioned. John Berger indicates that propaganda persuades us to believe in this change by showing us people who have obviously changed and are therefore enviable. This enviable state constitutes glamour and publicity is the process of creating glamour [12]. As for "glamour" in propaganda, we can think of the physical attractiveness of celebrities in posters, and "beauty is a recommendation that is more important than any letter of introduction" [13]. In Advertisements, the charm and appearance attractiveness displayed by celebrity endorsers' postures have a positive impact on product sales and consumers' understanding of products; publicity maximizes the glamour. Appearance attractiveness can change consumers' attitudes or views. This is also a factor related to the degree of matching: celebrities' superior appearance can be commensurate with products and increase masses' willingness to buy. Celebrities try to maximize their appeal to the public in product marketing.

Consumers' attitude towards brands and celebrities can be regarded as a definition and general evaluation of commodities. It will change due to advertising campaigns or celebrity endorsement and gradually stabilize over time. Consumer attitudes are shaped and established in brand consistency and celebrity positive and negative news. In the face of celebrities with high popularity, consumers will connect their identity with the brand and verify the publicity credibility. The recognition of celebrities will be transformed into the brand and produce a corresponding positive attitude, so as to have a high willingness to buy goods. The negative news of celebrities will make consumers feel the same negative about the brand they endorse. Purchase intention refers to the use of products purchased in the future. Before the purchase intention, consumers have a preliminary view on the product or endorser. Purchase intention is affected by the attractiveness of advertising, and it has a positive relationship with the endorser indirectly. Celebrity endorsement, as one of the most effective ways to influence consumers, continues to affect consumers' purchasing power. During endorsement, celebrities and consumers establish contact through the endorsed products, and fans can also experience the experience or lifestyle of celebrities. In order to follow and emulate their favorite celebrities, they believe that the quality of products is guaranteed by celebrities, and choose to believe in the products in publicity. This sort of celebrity-consumer relationship is called "celebrity bricolages" or "celebrity-scapes" [14] Celebrities are considered to enjoy a high quality of life, and some of their behaviors will become the standard for ordinary consumers to strive to improve their quality of life. Nowadays, consumers are rapidly making 
attitudes and reactions to unreliable and unrealistic brands, and the behavior of blindly following celebrities is decreasing [15]. For celebrity endorsement, consumers make rational decisions based on their understanding and trust of the product.

\section{CONCLUSION}

Celebrity is a crucial part of our entertainment activities and commercialization. It is more like a bridge to receive the public's attention and the media's favor and recognition of the image. Therefore, it can be said that the birth and success of celebrity is inseparable from the public and the media. They promote celebrities as far as the eye can see. From the example of Li Jiaqi, a basic fact can be seen that is a representative of ordinary people achieve success through publicity step by step. In today's mixed social media, he stands out, chooses the right direction, and makes perfect use of the visual communication mode of live video to make products famous and maximize their value. Through Li Jiaqi and the app Pindo, things that are cheap, accurate and easy to trust will be sought after. This reflects the severe economic situation and people's pursuit of suitable products and presents that popularity and credibility in advertising are two key essences as well. Advertisements often show cultural values. Celebrity is a well-packaged product cooperating with the product company and become the biggest manifestation of glamour in the promotion. They radiate their charm to attract consumers, and make consumers trust through the high matching degree between celebrities and products. Celebrity endorsements communicate with consumers, which promotes the dissemination and development of economy and culture, increases the trust of ordinary people or fans in the brand, resulting in a positive attitude and an increase in purchase intention.

Throughout the whole field of celebrity endorsement, all onlookers including ordinary audience and media use their attention to constitute the value and achievements of all celebrities and extend their attention to the products endorsed by celebrities, which is the transformation of their vision from one commodity to another. The attracted masses and fans will support consumption and promote economic development. Nevertheless, rational audiences, after satisfying their own visual needs and considering maximizing their benefit, are likely not to contribute to the celebrity's expenditure of money. After ensuring that celebrity advertisements attract a large amount of public attention, enterprises still needs to put more stamina on bringing in high demand, good quality, clear purpose and creative products, so that attention-grabbing celebrity posters can fully realize their value. Similarly, the influence of domestic media in various forms is huge, and it is easy for teenagers to be blindly consumed by strong propaganda and trust of their favorite celebrities before mature outlooks are formed Therefore, teenagers should have a correct consumption concept, treat celebrity endorsements rationally and choose to purchase products according to their needs.

\section{REFERENCES}

[1] Beller, J. (2021). Paying Attention. Cabinetmagazine.Org. Retrieved September 26, 2021, from https://cabinetmagazine.org/issues/24/beller.php

[2] McCracken, G. (1989). Who is the celebrity endorser? Cultural foundations of the endorsement process. The Journal of Consumer Research, 16(3), 310.

[3] Parmar, Y., Ghuman, M. K., \& Mann, B. J. S. (2020). The match-up between celebrity associations and product type. Journal of Creative Communications, 15(1), 65-89.

[4] Didi-Huberman, G. (2021). People exposed, people as extras. Radicalphilosophy.Com. Retrieved September 26, 2021, from

https://www.radicalphilosophy.com/article/peopleexposed-people-as-extras

[5] Emeraldinsight.Com. (2021.). Retrieved October 5, 2021 , from https://books.emeraldinsight.com/resources/pdfs/ch apters/9781787560796-TYPE23-NR2.pdf

[6] Abidin, C. (2018). Internet celebrity: Understanding fame online. Emerald Publishing. https://wikimili.com/en/Internet_celebrity

[7] Wanying, L., Siying, L., \& Xinxin, C. (2015). The impact of online shopping on the economy. market conditions(27), 57-57.

[8] Look closely at Alibaba and the financial results, everywhere each other's shadow. (n.d.). Retrieved October 5, 2021, from Baidu.com website:

https://baijiahao.baidu.com/s?id=16674438678396 $55058 \& w f r=$ spider $\&$ for $=p c$

[9] McCracken, G. (1989). Who is the celebrity endorser? Cultural foundations of the endorsement process. The Journal of Consumer Research, 16(3), 310.

[10] Bergkvist, L., \& Zhou, K. Q. (2016). Celebrity endorsements: a literature review and research agenda. International Journal of Advertising, 35(4), 642-663.

[11] Parmar, Y., Ghuman, M. K., \& Mann, B. J. S. (2020). The match-up between celebrity 
associations and product type. Journal of Creative Communications, 15(1), 65-89.

[12] John Berger / ways of seeing, episode 4 (1972). (2012, October 9). Youtube. https://www.youtube.com/watch?v=5jTUebm73IY

[13] Jamil, R. A., \& Hassan, S. R. ul. (2014). Influence of celebrity endorsement on consumer purchase intention for existing products: a comparative study. Journal of Management Info, 1(4), 1-8.

[14] Min, J. H. J., Chang, H. J. J., Jai, T.-M. C., \& Ziegler, M. (2019). The effects of celebrity-brand congruence and publicity on consumer attitudes and buying behavior. Fashion and Textiles, 6(1). https://doi.org/10.1186/s40691-018-0159-8

[15] Garthwaite, C. L. (2014). Demand spillovers, combative advertising, and celebrity endorsements. American Economic Journal. Applied Economics, 6(2), 76-104. 